\title{
A direita que saiu do armário: a cosmovisão dos formadores de opinião dos manifestantes de direita brasileiros
}

\section{Débora Messenberg*}

Resumo: O artigo procura desvelar a cosmovisão (weltanschauung) dos principais formadores de opinião dos manifestantes de direita brasileiros, que foram às ruas ao longo do ano de 2015. O trabalho pautou-se em pesquisa multimétodos, construída a partir do levantamento das postagens emitidas por esses atores sociais em suas páginas no Facebook, durante o ano em foco, além de matérias de suas autorias publicadas em blogs, jornais e revistas, como também vídeos de suas entrevistas e hangouts. Organizaram-se, ainda, dois grupos focais compostos por francos apoiadores e participantes dos referidos protestos, no intuito de compreender de que maneira a cosmovisão desses formadores de opinião foi efetivamente compartilhada pelos manifestantes de direita em 2015. Na análise dos dados coletados, optou-se pela sistematização de determinados campos semânticos, constituídos por certas ideias-força que se apresentam de forma regular e repetitiva no discurso desses agentes sociais. Funcionam, assim, como "chaves de leitura" para as interpretações da conjuntura política nacional e orientadores de suas ações. São eles: o antipetismo, o conservadorismo moral e os princípios neoliberais.

Palavras-chave: cosmovisão (weltanschauung), direita, formadores de opinião, manifestantes de 2015, campos semânticos.

A s manifestações que levaram centenas de milhares de pessoas às ruas nas principais cidades brasileiras, durante os meses de março, abril e agosto de 2015, trouxeram à luz o ativismo de certos tipos de atores sociais, que há décadas não participavam de forma tão intensa na arena pública. Tais manifestações revelaram a presença privilegiada de grupos de perfil conservador, os quais - e a despeito de suas clivagens internas em termos de tonalidades ideológicas - expuseram publicamente conviç̧ões de cunho segregador e autoritário.

Diversas pesquisas vêm sendo desenvolvidas na direção da caracterização desses manifestantes, de seus perfis ideológicos, bem como das organizações e instituições sociais que Ihes dão suporte (Ortellado, 2015; Telles, 2015b; Tatagiba et alii, 2015). Entretanto, pouco ainda se tem clareza sobre as configurações simbólico-discursivas que orientam cognitiva e normativamente a ação de tais atores sociais. É no sentido de trazer contribuição para este debate que o presente trabalho apresenta os resul-
Recebido: 13.05 .17

Aprovado: 18.09 .17

\author{
* Doutora, \\ Universidade de \\ São Paulo, 2000 \\ Porfessora associada \\ 1 de sociologia, UnB. \\ <deboramess@ \\ gmail.com>.
}


1. A noção de cosmovisão (Weltanschauung) aqui adotada fundamentase no sentido weberiano (1992), o qual a relaciona aos valores ou princípios culturais que embasam as concepções do universo e das filosofias de vida de uma sociedade ou grupo. Além disso, como aponta Weber: "[...] cosmovisões nunca podem ser o resultado de um avanço do conhecimento empírico, e que, portanto, os ideais supremos que nos movem com a máxima força possível, existem, em todas as épocas, na forma de uma luta com outros ideais que são, para outras pessoas, tão sagrados como o são para nós outros" (Weber, 1992: 113). tados de investigação, que procurou compreender a cosmovisão (Weltanschauung) ${ }^{1}$ dos principais formadores de opinião dos manifestantes que foram às ruas, ao longo do ano de 2015, para protestar contra a corrupção no país, opor-se de maneira frontal ao Partidos dos Trabalhadores (PT) e às suas políticas sociais e de direitos, além de exigir o impeachment da presidenta Dilma Rousseff.

Parte-se do pressuposto que os ativistas que foram as ruas nos dias 15 de março, 12 de abril e 16 de agosto de 2015 encontram-se posicionados ideologicamente no que se convencionou chamar de à direita do espectro político. Direita e esquerda são conceitos polissêmicos e, para alguns analistas, pouco úteis para a compreensão da vida política nas sociedades contemporâneas. Entretanto, e contrários a essa presunção, colocamo-nos entre aqueles que defendem não só a atualidade e a funcionalidade desses conceitos, como sua centralidade para o entendimento da vida cotidiana e para a construção de identidades no agir político.

Dentre os principais defensores da manutenção interpretativa da díade esquerda e direita, encontramos Norberto Bobbio. Em seu já clássico ensaio Direita e esquerda: razões e significados de uma distinção política (1995), Bobbio propõe uma série de princípios que - segundo ele - encontram-se claramente presentes e são distintivos das ideologias de esquerda e de direita. Embora saliente que a direita e a esquerda não se apresentam concretamente na política como blocos homogêneos e/ou coerentes, argumenta que se pode admitir de forma ampla que a esquerda se orienta essencialmente para a promoção da igualdade entre os homens e para a mudança da ordem social, enquanto a direita concebe a desigualdade como algo intrínseco à humanidade e mantém o apego às tradições e à preservação do ordenamento societário. Anexam-se a esses princípios, outros valores observáveis nos países industrializados e que recobrem algumas ideias recorrentes.

Na esquerda, dá-se o primado do igualitarismo sobre os direitos da propriedade e do livre comércio, o racionalismo, o laicismo, a crítica das limitações ético-religiosas, a inexistência de conceitos absolutos de bem e mal, o desprezo à oligarquia, a preservação do meio ambiente e os interesses dos trabalhadores, que devem prevalecer sobre a necessidade de crescimento econômico, o antifascismo e a identificação permanente com as classes inferiores da sociedade.

A direita - como aponta Bobbio (1995) - move-se por outros ideais que envolvem: o individualismo, a supremacia da propriedade privada e da livre iniciativa, a intuição, a primazia do sagrado, a valorização da ordem e da tradição, o elogio da nobreza e do heroísmo, a intolerância à diversidade étnica, cultural e sexual, o militarismo e a 
defesa da segurança nacional, o crescimento econômico em detrimento da preservação ambiental e dos interesses imediatos dos trabalhadores, o anticomunismo e a identificação permanente com as classes superiores da sociedade.

Observa-se, assim, que para além do campo político, as cosmovisões da esquerda e da direita constituem e se espraiam no "campo metapolítico das relações sociais cotidianas e da luta cultural" (Pierucci, 1990: 11). São, portanto, quadros de referência a partir dos quais os indivíduos interpretam e interagem com o mundo, estabelecendo significados à sua existência e explicando a "ordem das coisas".

No campo ideológico da direita, foco central da presente investigação, há um núcleo fundante em seu programa historicamente construído: o conservantismo. Como bem esclarece Antônio Pierucci,

\begin{abstract}
o conservantismo é antes de mais nada uma proposta de sociabilidade. [...] é uma combinação de práticas (de distinção, hierarquização, desprezo, humilhação, intolerância, agressão, profilaxia, segregação), de discursos espontâneos e discursos doutrinários abrangendo a esfera pública e a vida privada, de soluções políticas e econômicas mas também de restauração moral, de racionalizações e afetos, princípios e estereótipos, fantasmas e preconceitos girando em torno ou nascendo em raio de uma obsessão identitária, isto é, de uma necessidade sempre autorreferida de preservação à outrance de um "eu" ou um "nós" ameaçado [...] (Pierucci,1990: 10).
\end{abstract}

\title{
Procedimentos metodológicos
}

Para a realização do trabalho, adotou-se uma estratégia metodológica pautada em pesquisa multimétodos, a qual incluiu, em um primeiro momento, a identificação dos principais movimentos sociais que deram suporte logístico e ideológico às manifestações, a suas lideranças e a outros formadores de opinião centrais, que as promoveram e as incentivaram em seus respectivos campos atuação: as redes sociais, o midiático e o parlamentar. A pesquisa selecionou e analisou, em função de sua importância e capacidade de reverberação de seus conteúdos, os posicionamentos dos seguintes atores sociais:

Movimentos sociais - Movimento Brasil Livre (MBL), Vem pra rua e Revoltados Online.

Lideres desses movimentos - Kim Kataguiri, Fernando Holiday, Rogério Chequer, Marcello Reis e Beatriz Kicis. 
2. Para maiores informações sobre o software Netvizz acesse: <https://wiki. digitalmethods.net/ Dmi/ToolNetvizz>.

3. As postagens do movimento Revoltados Online foi suspensa algumas vezes ao longo do ano de 2015, devido à não adesão dos administradores da página aos termos de compromisso exigidos pelo Facebook.
Jornalistas - Olavo de Carvalho, Reinaldo Azevedo, Raquel Sheherazade, Felipe Moura Brasil e Rodrigo Constantino.

Deputados federais - Jair Bolsonaro e Marco Feliciano.

Na etapa seguinte, realizou-se o levantamento das postagens emitidas por esses atores sociais em suas páginas no Facebook, ao longo do ano de 2015, além de matérias de suas autorias publicadas em blogs, jornais e revistas, assim como vídeos de suas entrevistas e hangouts disponíveis no YouTube. O Netvizz ${ }^{2}$, software de coleta de dados de redes sociais, projetado especificamente para a extração e análise de dados do Facebook, foi o selecionado para o levantamento das informações compartilhadas pelos formadores de opinião investigados em suas páginas públicas do Facebook. Tal processo resultou na coleta e análise de um total de 18.923 publicações, assim distribuídas:

Movimento Brasil Livre (MBL), 4.996 postagens;

Vem Pra Rua, 1.723 postagens;

Fernando Holiday, 1.159 postagens;

Kim Kataguiri, 1.051 postagens;

Olavo de Carvalho, 2.175 postagens;

Reinaldo Azevedo, 1.882 postagens;

Felipe Moura Brasil, 1.563 postagens,

Rachel Sheherazade, 548 postagens;

Marco Feliciano, 2.178 postagens; e

Jair Bolsonaro, 318 postagens.

O uso desse software somente não foi possível no levantamento de dados relativos àqueles atores que, por não apresentarem durante o ano de 2015 páginas públicas na rede social, tiveram coletadas suas páginas pessoais, as respectivas postagens no Facebook. Esses foram, especialmente, os casos de

Rodrigo Constantino, 686 postagens;

Rogério Chequer, 171 postagens;

Marcelo Reis, 152 postagens; e

Revoltados Online, 135 postagens ${ }^{3}$. 
É de se observar que, conforme a data na qual se realiza o levantamento das informações, o número final de postagens nas páginas pessoais do Facebook pode apresentar alguma alteração, em virtude da possibilidade de retirada de certas mensagens e de acordo com a vontade particular do responsável pela mesma. Isso, porém, não trouxe distorções significativas para o presente trabalho, na medida em que o foco da investigação encontra-se direcionado para a análise qualitativa dos conteúdos emitidos, assim como o número das postagens coletadas e analisadas é deveras substancial, mesmo em relação às páginas pessoais.

Como último procedimento metodológico, organizaram-se dois grupos focais, compostos por francos apoiadores e participantes das manifestações de direita em 2015, no intuito de se verificar a maneira pela qual a cosmovisão desses formadores de opinião foi efetivamente compartilhada por tais manifestantes e como ela influenciou suas participações nos referidos protestos. Para garantir maior qualidade e fidedignidade às informações coletadas, procurou-se assegurar certa diversidade em termos de gênero, faixa etária, renda, nível educacional e profissão entre os participantes dos dois grupos. A técnica de pesquisa dos grupos focais revelou-se uma combinação produtiva entre observação participante e entrevistas em profundidade. Este procedimento apresentou-se como recurso adequado para a compreensão do processo de construção das percepções, atitudes e representações desses grupos sociais (Veiga \& Gondim, 2001). Pretendeu-se, com isso, reagregar o espaço crítico dentro do qual se desenvolveu o fenômeno em análise. Em vez de definir e tentar explicar os atores por meio de atributos estáveis, optou-se por mostrar de que modo "os atores elaboram discursos sobre sua própria ação" (Boltanski, 2000: 55).

Na interpretação dos dados coletados, definiu-se como s mais adequada a sistematização de determinados campos semânticos constituídos por certas ideias-força que se apresentam de forma regular e repetitiva no discurso desses agentes sociais. Deve-se esclarecer que o discurso é aqui compreendido na perspectiva de Dominique Maingueneau, ou seja:

Bem menos do que um ponto de vista, [o discurso] é uma organização de restrições que regulam uma atividade específica. Sua enunciação não é uma cena ilusória onde seriam ditos conteúdos elaborados em outro lugar, mas um dispositivo constitutivo da construção do sentido e dos sujeitos que aí se reconhecem (Maingueneau, 1993: 50).

Ou, como nos lembra Rosalind Gill (2011), a linguagem é tanto construtiva quanto construída. Isso significa que nenhuma linguagem é neutra, ao contrário, o discurso 
é parte essencial da construção da vida social. As formas, como as pessoas, que concebem a realidade são, então, histórica e culturalmente específicas. Compreendemos o mundo não por sua natureza essencial, mas pelos processos sociais. Tendo em vista o aspecto prático de todo discurso, os atores sociais estão continuamente orientando-se pelo "contexto interpretativo", no qual estão inseridos e construindo seus discursos para se ajustarem a ele. Reconhecer a importância do contexto na formulação dos argumentos não significa percebê-los como falácias deliberadas, pois a formulação de qualquer discurso implica estabelecer uma versão do mundo diante de versões competitivas.

\title{
Quem são os formadores de opinião dos manifestantes de direita brasileiros?
}

Identificam-se como formadores de opinião, lideranças reconhecidas por suas audiências e às quais

\begin{abstract}
se transfere a responsabilidade de organizar cognitivamente uma grande quantidade de informações sobre um mundo complexo, auxiliando o cidadão a adquirir e demonstrar a competência mínima que Ihe exige a política (Aldé: 2004: 46).
\end{abstract}

\section{A noção de enquadramento é aqui tomada no sentido goffmaniano (Goffman, 2012) ou seja, como "estruturas cognitivas, que organizam o pensamento, são compostas de crenças, atitudes, valores e preferências, bem como de regras a respeito de como ligar diferentes ideias. São esquemas que 'dirigem atenção para a informação relevante, guiam sua interpretação e avaliação, fornecem inferências quando a informação é falha ou ambígua, e facilitam sua retenção'" (Fiske \& Kinder, citados por Entman, 1989, apud Aldé, 2004: 47).}

São os emissores legitimados pelo meio social receptor, por serem distinguidos como dotados de opinião autorizada, identificados como agentes com grande competência interpretativa da realidade concreta e acesso privilegiado às informações consideradas relevantes. São eles, portanto, os pautadores dos interesses e das prioridades informacionais de sua audiência e intérpretes de sua vida cotidiana e da política.

No mundo contemporâneo os meios de comunicação de massa e as redes digitais constituem-se nos espaços privilegiados para a construção dos enquadramentos ${ }^{4}$, os quais as pessoas recorrem para organizar e selecionar suas atitudes políticas. Tais enquadramentos são produzidos de forma interativa, isto é, são resultados de um processo de mão dupla entre os emissores e os receptores da informação, o qual envolve tanto a repetição de padrões interpretativos e compreensivos de forma seletiva e manipulatória, quanto a de valores e símbolos dominantes no senso comum, que são assim retroalimentados e/ou reformados de forma dinâmica.

Para fins deste estudo, o foco será direcionado para a discussão dos principais enquadramentos elaborados pelos mais influentes formadores de opinião dos manifestantes de direita brasileiros (movimentos sociais, jornalistas e políticos). Tais estruturas cognitivas, ao serem veiculadas pela mídia e pelas redes sociais, configu- 
ram-se em campos semânticos, compostos por ideias-força, que são adotados por esse público como "chaves de leitura" para a interpretação da conjuntura política nacional e orientadores de suas ações políticas.

De início, cabe traçar a identificação dos atores sociais selecionados como formadores de opinião dos manifestantes de direita brasileiros. À frente e em relação aos movimentos sociais, destacam-se: o Movimento Brasil Livre (MBL), o Vem Pra Rua, e o Revoltados Online.

O MBL em sua página no Facebook (<www.Facebook.com/mblivre>) apresenta-se como

uma entidade sem fins lucrativos que visa mobilizar cidadãos em favor de uma sociedade mais livre, justa e próspera. Defendemos a Democracia, a República, a Liberdade de Expressão e de Imprensa, o Livre Mercado, a Redução do Estado e a Redução da Burocracia.

A primeira postagem do Movimento Brasil Livre no Facebook foi no mês de junho de 2013 e, em 15 de março de 2015, a página contava com cerca de 65,5 mil fãs. Os coordenadores nacionais de maior visibilidade do MBL são os universitários paulistas Kim Kataguiri e Fernando Holiday.

A página do movimento Vem Pra Rua Brasil no Facebook (<www. Facebook.com/ VemPraRuaBrasil.org>) foi criada em outubro de 2014, poucos dias antes do segundo turno das eleições presidenciais. Em sua autodefinição na rede, o movimento conclama os seguidores a vir para rua e "manifestar sua indignação conosco". "Nossa bandeira é a Democracia, a Ética na Política e um Estado Eficiente e Desinchado". No dia 15 de março de 2015, a página exibia aproximadamente 331 mil fãs. O coordenador nacional do Vem Pra Rua é o empresário paulista Rogério Chequer.

O movimento Revoltados Online (<www. Facebook.com/revoltadosonline/>) apresenta-se, desde agosto de 2010, como uma comunidade no Facebook. Na rede intitula-se como: "uma organização de iniciativa popular de combate aos corruptos do poder". Em 15 de março de 2015, o Revoltados Online contava com cerca de 707 mil fãs. O fundador do movimento é o administrador de empresas paulista Marcello Reis e tem ainda como figura de destaque a procuradora do Distrito Federal, Beatriz Kicis. O movimento exibe em suas postagens no Facebook como seus ícones, o deputado Jair Bolsonaro (PSC-RJ), o qual é carinhosamente chamado por "Bolsomito" e o jornalista Olavo de Carvalho, reverenciado enquanto o "oráculo" ou "professor". No que diz respeito à caracterização dos líderes dos movimentos acima apontados, convém preliminarmente salientar o intenso intercâmbio de postagens entre esses atores nas redes sociais. Isso revela uma evidente proximidade ideológica entre 
eles, embora sejam observadas diferenças significativas em termos da sofisticação intelectual, níveis de agressividade e o teor conspiratório em seus discursos.

Kim Patroca Kataguiri nasceu em 1996, na cidade de Salto (SP). Atualmente mora em Santo André (SP), local para onde se mudou quando foi aprovado no curso de economia da Universidade Federal do ABC. O curso foi abandonado logo no primeiro ano, por ter ele julgado que: "lá ensinam Marx e Keynes e ignoram os pensadores liberais, como Milton Friedman, Friedrich Hayek, Carl Menger e Ludwig von Mises. Tem professor que nem conhece esses caras" (<http://ultimosegundo.ig.com.br/politica/2015-03-12/roqueiro-e-ativista-na-web-lider-anti-dilma-defende-privatizar-saude-e-educacao.html>). Sua página no Facebook contava, em outubro de 2016, com mais de 318 mil curtidas, onde ele se apresentava como coordenador nacional do MBL, colunista da Folha de S. Paulo, do Huffpost Brasil e comentarista político da rádio $A B C$.

Fernando Silva Bispo (Fernando Holiday) nasceu em 1996, na cidade de São Paulo, e apresenta-se em sua página no Facebook como coordenador Nacional do Movimento Brasil Livre e vereador eleito pela cidade de São Paulo, com 48.055 votos. Ostentava, na rede, em outubro de 2016, mais de 171 mil curtidas. Foi aprovado para o curso de filosofia da Universidade Federal de São Paulo (Unifesp), mas não chegou a cursá-lo. Em novembro de 2015 e da tribuna da Câmara dos Deputados resumiu assim seu currículo pessoal e suas crenças:

A esquerda que governou este país só sabe reclamar, só sabe se vitimizar. Eu quero dizer aqui, que eu, como negro, como pobre, como homossexual, não me vitimizo. Eu venho aqui, eu vou a qualquer lugar, porque eu quero lutar, eu quero alcançar o meu sucesso, não me rastejar atrás do Estado (<https://youtu.be/QpmfMK6D_m4>).

Rogério Chequer nasceu em 1968, na cidade de São Paulo (SP). É um empresário que se descreve, em sua página no Facebook (2.023 seguidores em outubro de 2016), como trabalhador da State of the Art Presentation (Soap), definida por ele "como a empresa de soluções de comunicação em momentos decisivos" (<http:// istoe.com.br/409231_O.S+MOVIMENTOS+DE+RUA+VIERAM+PARA+FICAR+/>). Chequer é formado em engenharia de produção pela Escola Politécnica da Universidade de São Paulo e se autodenomina como o único porta-voz do movimento Vem Pra Rua. Contudo, em março de 2015 e, em suas palavras, o Vem Pra Rua já contava com o apoio direto de 2.500 pessoas, coordenadas por cerca de 150 líderes espalhados pelas diversas capitais do país, os quais cuidavam diretamente da administração e comunicação do movimento. "Não somos uma empresa, somos um grupo de pes- 
soas que tem um propósito em comum. Temos líderes de todos os tipos e de todas as classes sociais" (<https://youtu.be/oZAn4KthDJ4>).

Marcello Cristiano Reis, nascido em 1974, na cidade de São Paulo (SP), é administrador de empresas e fundador do movimento Revoltados Online. Reis era seguido, em outubro de 2016, em sua página no Facebook, por cerca de 308 mil pessoas. Lá se encontravam registrados de forma insistente, os seguintes lemas: "Guerra entre o Bem e o Mal", "só temos Deus na nossa frente" e "não vamos desistir do Brasil". De acordo com ele, o Revoltados Online financiava-se basicamente a partir da venda de "kits pró-impeachment", os quais eram compostos por camisetas com mensagens a escolher e entre as mais emblemáticas: "Impeachment já", "Fora Dilma e leve o PT junto com você", "100\% anticomunismo", "Deus, Família, e Liberdade”, "Keep calm and say no to communism in Latin America", "Fraude: impeachment já", além de um boné com a logomarca do movimento e cinco adesivos com os dizeres "Fora Dilma".

Beatriz Kicis Torrents de Sordi, outra figura de destaque no movimento Revoltados Online, é formada em direito pela Universidade de Brasília (UnB), procuradora aposentada do Ministério Público Federal do Distrito Federal e exibia, em outubro de 2016, mais de 43 mil curtidas em sua página no Facebook. Na mesma rede, Kicis retrata-se como:

\begin{abstract}
uma cidadã brasileira, advogada, procuradora do Distrito Federal, mãe de dois filhos, e que tem se dedicado à atividade política apartidária, na luta incansável contra o Foro de São Paulo, organização criminosa, fundada por Lula e Fidel Castro nos anos 90. Ao tomar conhecimento deste Foro de São Paulo e seu projeto de implantação do comunismo na América Latina e, ao perceber que a grande mídia silencia sobre esse tema e tantos outros, decidiu que era sua obrigação de cidadã compartilhar essas informações com os demais brasileiros. Essa página é um espaço para essa missão (<https://pt-br.Facebook.com/biakicisoficial>).
\end{abstract}

Olavo Luiz Pimentel de Carvalho nasceu em Campinas, no ano de 1947. Não possui formação universitária, mas se define como filósofo, ensaísta e escritor brasileiro. Em sua página no Facebook, seguida em outubro de 2016, por 288.689 pessoas, exibe a seguinte apresentação: "apenas um véio lôco. Lôco o bastante para ser sincero". Considerado como o mestre e o grande inspirador da nova geração de direita na rede, Carvalho escreve e edita, desde 2002, o site Mídia sem Máscara. Nele concentra suas matérias, em geral polêmicas, sobre o que define como um combate incansável ao comunismo internacional, aos grupos de esquerda e aos meios intelectuais e midiáticos brasileiros. Responde pessoalmente aos comentários em sua página no Facebook, possui mais de 6 mil seguidores em seu canal no YouTube e 
5. A Atlas Network, anteriormente conhecida como o Atlas Economic Research Foundation, é uma organização sem fins lucrativos sediada nos Estados Unidos. O grupo tem como missão declarada:

"fortalecer o movimento da liberdade em todo o mundo por meio da identificação, formação e apoio a indivíduos com potencial para fundar e desenvolver organizações independentes eficazes." Em 2015, a Atlas Network se posicionava no 570 lugar entre as Top Think Tanks dos Estados Unidos (McGann, 2015). participa quinzenalmente de Hangouts. Carvalho publicou 21 livros e estampa uma enorme produção de artigos, ensaios e palestras. Mora, desde 2005, em Richmond, no estado da Virgínia (EUA), onde mantém fortes vínculos de financiamento com o Independent Republican Institute (IRI), vinculado ao Partido Republicano norte-americano e com a Atlas Network ${ }^{5}$.

José Reinaldo de Azevedo e Silva, nascido em 1961, em Dois Córregos (SP), formado em jornalismo pela Universidade Metodista de São Paulo (UMSP), ostentava, em outubro de 2016, mais de 301 mil curtidas de sua página no Facebook. Expõe na rede como sua citação preferida, a seguinte frase: "escreve o que quer, ainda que não queiram". É colunista do jornal Folha de S. Paulo, sendo também comentarista e analista político da Rede TV. De março de 2014 até maio de 2017, comandou diariamente o programa "Os pingos nos Is", na Rádio Jovem Pan, bem como administrava um blog hospedado no site da Revista Veja, o qual exibia, em média, cerca de 150 mil acessos diários. Publicou cinco livros nos últimos anos, assim intitulados: Contra o consenso (2005), O país dos Petralhas (2008), Máximas de um país mínimo (2009), O país dos Petralhas 2 (2012) e Objeções de um rottweiller amoroso (2014), cujas temáticas envolvem uma crítica ácida à política brasileira, dirigidas especialmente aos governos do PT, assim como aos ambientes acadêmicos e jornalísticos nacionais.

Raquel Sheherazade Barbosa, nascida em 1973, em João Pessoa (PB), é jornalista e radialista formada em comunicação social pela Universidade Federal da Paraíba (UFPB). Atualmente ancora o Jornal da Manhã, na rádio Jovem Pan e o telejornal SBT Brasil, no SBT. Em sua página no Facebook constavam, em outubro de 2016, mais de 2 milhões e 400 mil curtidas. Sheherazade é louvada por seus seguidores nas redes sociais, em virtude de sua disposição em se colocar como protetora contumaz da moral cristã e dos valores tradicionais da família brasileira; além de reconhecerem nela uma crítica feroz aos defensores dos direitos humanos no Brasil e aos partidos e governos de esquerda. Do lado de seus oponentes, a jornalista é acusada de "desafiar o código de ética dos jornalistas, incitar a intolerância e o crime contra minorias sociais" (<http://www.cartacapital.com.br/blogs/midiatico/sob-pressao-sbt-barra-comentarios-rachel-sheherazade-4060.html>). Em 2015, lançou o livro intitulado O Brasil tem cura, o qual traz em sua sinopse, a pretensão da autora em fazer "uma radiografia, sem máscaras, da nossa pátria" e "indicar soluções para os problemas que adoecem o país". Em suas palavras:

O país só será passado a limpo, se cada brasileiro fizer a sua parte e passar a agir com integridade inegociável, ensinando essa postura às futuras gerações (Sheherazade, O Brasil tem cura: contracapa). 
Felipe Moura Brasil é um jornalista carioca, nascido em 1981, e que atua como colunista no site O Antagonista, criado em 2015, pelos jornalistas Diogo Mainardi e Mário Sabino. Comanda ainda na rádio Jovem Pan e, em substituição ao jornalista Reinaldo Azevedo, o programa diário "Os pingos nos Is". Entre os anos de 2013 e 2017, escreveu uma das colunas mais lidas da Revista Veja, atuando também como comentarista no programa "Estúdio Veja". Foi o organizador do livro O mínimo que você precisa saber para não ser um idiota (Record, 2013), uma coletânea de 193 textos de autoria de Olavo de Carvalho, cuja vendagem já ultrapassou a soma de 120 mil cópias. Sua página no Facebook registrava, em outubro de 2016, mais de 200 mil seguidores. Os principais conteúdos de suas matérias, publicadas ao longo do período considerado, recaem sistematicamente numa crítica incisiva ao governo Dilma, em denúncias de corrupção envolvendo o Partido dos Trabalhadores, assim como ampla defesa e divulgação das mobilizações favoráveis ao impeachment.

Rodrigo Constantino dos Santos nasceu no Rio de Janeiro, em 1976, e estudou economia na Pontifícia Universidade Católica do Rio de Janeiro (PUC-RJ). É atualmente o presidente do Instituto Liberal, organização sem fins lucrativos, fundada em 1983, pelo empresário Donald Stewart Jr., com o objetivo de difundir os valores liberais da livre iniciativa, da propriedade privada e da responsabilidade individual. É ainda um dos idealizadores do Instituto Millenium (Imil), entidade igualmente autodenominada como sem fins lucrativos e sem vinculação político-partidária, constituída por intelectuais e empresários, os quais a retratam como um think tank que

promove valores e princípios que garantem uma sociedade livre, com liberdade individual, direito de propriedade, economia de mercado, democracia representativa, Estado de direito e limites institucionais à ação do governo (<http://www.institutomillenium. org.br/institucional/quem-somos/).

Constantino era seguido, em outubro de 2016, por 145.521 pessoas no Facebook, onde se apresenta com a seguinte citação: "um soldado incansável na luta pela liberdade, sem medo da patrulha e do politicamente correto".

Jair Messias Bolsonaro, nascido em Campinas, em 1955, revela-se em sua página no Facebook, como capitão do Exército Brasileiro e deputado federal mais votado do estado do Rio de Janeiro, com 464.565 votos. Bolsonaro exibia, em outubro de 2016, mais de 3 milhões e 350 mil curtidas de sua página. Encontra-se em sua sétima legislatura na Câmara dos Deputados. Elegeu-se pelo Partido Progressista (PP) em sua última disputa eleitoral, mas atualmente está filiado ao Partido Social Cristão 
(PSC). Bolsonaro afirma, em seu site pessoal, que suas bandeiras estão solidamente fincadas na defesa da família e do Estado Brasileiro. No atual mandato,

destaca-se na luta pela proibição do chamado "kit gay" (cartilhas destinadas às escolas do ensino fundamental) com forte viés de apologia ao homossexualismo e pela redução da maioridade penal (<http://www.bolsonaro.com.br/>).

Em virtude de seu grande carisma frente ao eleitorado, Bolsonaro conseguiu eleger seus três filhos do primeiro casamento para mandatos parlamentares: Carlos Bolsonaro (vereador do Rio de Janeiro pelo PSC), Flávio Bolsonaro (deputado estadual do Rio de Janeiro pelo PSC) e Eduardo Bolsonaro (deputado federal de São Paulo pelo PSC). Juntos escrevem um blog denominado "A família Bolsonaro" (<http://familiabolsonaro.blogspot.com.br>), no qual divulgam suas atividades parlamentares, criticam diretamente os partidos e políticos de esquerda, além de se apresentarem como a alternativa da direita para dar "um novo rumo para o Brasil".

Marco Antônio Feliciano nasceu em 1972, na cidade de Orlândia (SP). Em sua página no Facebook, na qual constavam, em outubro de 2016, mais de 3 milhões e 900 mil curtidas, descreve-se como o presidente da Igreja Assembleia de Deus Catedral do Avivamento, conferencista internacional, escritor, cantor e deputado federal. Encontra-se em seu segundo mandato na Câmara dos Deputados, tendo sido eleito pelo PSC-SP. Nas últimas eleições para a Câmara dos Deputados, Feliciano foi o terceiro candidato mais votado do estado de São Paulo e aquele que obteve o maior número de votos da bancada evangélica (398 mil e 87 votos); reconhece-se como um defensor férreo do ideário tradicional da moral cristã, principalmente ao que se refere à sua luta pessoal para a aprovação do projeto de "cura gay" e a sua oposição à prática do aborto, ao controle da natalidade, à união civil entre pessoas do mesmo sexo e à ideologia de gênero nas escolas. Em suas palavras: "é preciso salvar a família brasileira!" (<https://youtu.be/UCA8Z1qDqbM>). Além de pastor, Feliciano é empresário, autor de 18 livros e produtor de DVDs com mensagens de autoajuda, que já venderam mais de 600 mil cópias.

Feita a caracterização geral dos perfis dos formadores de opinião aqui selecionados, cumpre agora elucidar os enquadramentos formulados por esses atores sociais, os quais, após serem difundidos pela mídia e redes sociais, acabam por funcionar como quadros de referência que permitem aos seus seguidores dar coerência às suas opiniões, escolhas e ações. 


\title{
Os campos semânticos e as ideias-força em discussão
}

A atual cosmovisão da direita no Brasil, compreendida como um universo multidimensional, o qual abarca diferentes tonalidades ideológicas e emissões discursivas, exige esforço e cuidado redobrados do pesquisador para a sua decifração. Isso porque não se trata de um universo mental com contornos claros, nem fronteiras e limites bem definidos. Pelo contrário, como nos esclarece Antônio Flávio Pierucci, as diferentes posições e alinhamentos da direita

\begin{abstract}
não são peças de um quebra-cabeça que podem ir se encaixando como subconjuntos independentes, formando um todo harmonioso e confinado. Elas se interpenetram, reagem uma sobre a outra, se misturam às vezes, se fagocitam sempre, aqui se enriquecem, ali se anulam, aqui aparecem e ali se escondem, feito massas estelares, distintas, mas nem por isso menos nebulosas (Pierucci,1987: 40).
\end{abstract}

Não obstante e, segundo o autor, é possível acompanhar a formação dessas constelações de sentido a partir do inventário das ideias-força que se repetem e sustentam o discurso dos sujeitos investigados, acabando por configurar certos campos semânticos. Este foi, como já assinalado, o procedimento metodológico adotado

\section{QUADRO 1}

\section{CAMPOS SEMÂNTICOS}

\begin{tabular}{|c|c|c|}
\hline \multicolumn{3}{|c|}{ Campos semânticos } \\
\hline Antipetismo & Conservadorismo moral & Princípios neoliberais \\
\hline Ideias-força & Ideias-força & Ideias-força \\
\hline $\begin{array}{l}\text { Impeachment (Fora PT, } \\
\text { Fora Dilma, Fora Lula) }\end{array}$ & Família tradicional & Estado mínimo \\
\hline Corrupção & Resgate da fé cristã & $\begin{array}{l}\text { Eficiência do mercado } \\
\text { (privatização) }\end{array}$ \\
\hline Crise econômica & Patriotismo & $\begin{array}{l}\text { Livre iniciativa } \\
\text { (empreendedorismo) }\end{array}$ \\
\hline Bolivarianismo & Anticomunismo & Meritocracia \\
\hline & $\begin{array}{l}\text { Combate à criminalidade } \\
\text { / aumento da violência }\end{array}$ & Corte de políticas sociais \\
\hline & Oposição às cotas raciais & \\
\hline
\end{tabular}

Fonte: Pesquisa. 
neste trabalho, o qual resultou na descoberta de três campos semânticos centrais no discurso dos formadores de opinião dos manifestantes de direita nas grandes mobilizações de 2015, e que se fundam em torno de algumas ideias-força. O Quadro 1 abaixo é elucidativo para esta discussão.

O antipetismo é o campo semântico a reunir o maior número de emissões discursivas dos formadores de opinião aqui analisados, tanto em suas postagens no Facebook, durante o ano de 2015, quanto em seus sites, blogs, participações em entrevistas e hangouts. O Partido dos trabalhadores (PT) é, na visão desses atores sociais, o grande responsável por todas as mazelas que atingem o país. Ao PT é atribuída a responsabilidade tanto da crise econômica que nos assola mais diretamente nos últimos três anos, quanto ao que é reconhecido por eles como um dos principais, senão o principal problema do país: a corrupção. O combate à corrupção, entendida como uma valência no mundo contemporâneo, assume no discurso desses agentes a condição sinonímia de combate ao PT. Expressões como "Petrolão", "Petralhas", "Quadrilha do PT" abundam nos discursos desses formadores de opinião, consolidando a certeza entre os seus seguidores de que a corrupção, apesar de ser reconhecida como prática longeva na vida pública brasileira, foi erigida pelo PT como "prática de governo". A simbiose discursiva construída entre o PT e as noções de corrupção e crise foram também captadas em pesquisa realizada por Helcimara Telles (2015), em Belo Horizonte, no dia 12 de abril de 2015, junto aos manifestantes. Segundo a autora, mais do que protestarem contra a corrupção no país (36\% admitiram estar nas ruas por esse motivo), o tema que mais uniu os manifestantes foi o antipetismo.

Para eles, os principais males do Brasil são atribuídos aos governantes identificados como petistas. 91\% declararam que o PT fez um grande mal ao país e $82 \%$ deram nota 0 ao PT. $O$ antipetismo também pode ser encontrado no julgamento que fazem dos seus quadros: $81 \%$ consideram que Lula é um dos principais malfeitores do país, $82 \%$ concordam que Dilma também é uma das malfeitoras... (Telles, 2015a: 3).

Com uma perspectiva econômica tão desastrosa, o Brasil não vai escapar do rebaixamento. Perderemos em breve o selo de bom pagador, e, com isso, os investidores que ainda acreditam na nossa economia. Haverá uma fuga de investimentos que deverá piorar ainda mais a situação do país. Esse é o retrato da economia brasileira, sem filtro nem maquiagem fiscal. A verdade é que, sem pedaladas, a presidente não consegue entregar um orçamento positivo. Esse, meus caros, é o resultado da incompetência, dos gastos descontrolados, é o preço do vale tudo para vencer a última eleição. Essa é a consequência de 12 anos de desgoverno do PT. Esse é o 
preço de eleger uma fraude, chamada Dilma Rousseff. É um preço alto a ser pago, principalmente quando sabemos que o ônus é dividido entre todos os brasileiros: os que votaram e os que repudiaram a "presidenta-incompetenta." "Eu não mereço este Governo!" (Raquel Sheherazade, postagem Facebook 02 Set. 2015).

Você, brasileiro que não mete a carteira no bolso de ninguém, que vive com o suor do seu rosto, você que oferece aos seus filhos apenas aquilo que o seu trabalho pode comprar, você que tem senso de moral, você que tem decência, que não vive pendurado nas tetas públicas, que tem nojo desta corja que se apoderou do país, você pode chamar os petistas de ladrões... porque quem quer fazer as coisas vai atrás e consegue, não fica pendurado reclamando... os judeus eram as vítimas, os petistas são os algozes (Reinaldo Azevedo, postagem Facebook 22 Out. 2015).

DILMA, LULA E QUADRILHA DO PT VÃO PRA CUBA QUE TE PARIU... (Revoltados Online, postagem Facebook 16 Set. 2015).

Não chamem a Dilma de presidente, nem de presidenta: vc é uma vagabunda, usurpadora, ladra, bandida... que tá ocupando cargo indevidamente, sai daí! Seu Lula, a mesma coisa! Por que concedê-lo a dignidade de ex-presidente se todo mundo sabe que ele é apenas um ladrão? E que está trabalhando para poderes estrangeiros, tá trabalhando para Cuba, tá trabalhando pra Venezuela, tá trabalhando para Angola, não para o Brasil.... Até quando vamos aceitar isso? (Olavo de Carvalho, https://youtu.be/wnzhrr1RIT4).

As emissões discursivas acima selecionadas ilustram bem a conexão de sentidos entre as ideias-força que sustentam o antipetismo. Mais do que isso, revelam a virulência com que tais discursos foram proferidos e o seu caráter fascista ${ }^{6}$. A eleição de "bodes expiatórios" é um dos mais tradicionais mecanismos políticos para amenizar o ódio e as frustrações de parcelas da sociedade, que se veem ameaçadas diante daquilo que sentem como agressões ao mesmo tempo difusas e brutais ao seu mundo. Como nos ensina Raoul Girardet (1987), a demonização de um grupo social real ou imaginário é um dos pilares do "mito do complô", que assume função social explicativa das mais importantes no universo da política. Ao reduzir a uma única causalidade os acontecimentos desconcertantes e incômodos, finda por lhes restituir a inteligibilidade, minimizando a terrível angústia provocada pelo desconhecido. A personificação do mal (petistas, comunistas, imigrantes, judeus) permite, assim, o seu fácil reconhecimento e, por conseguinte, a vigilância e o combate. Ademais, encontrando-se encarnado, o mal reafirma a identidade dos grupos sociais que se consideram majoritários e apresenta-se como a antítese da "normalidade". Desse modo, fornecendo resposta ao que não se compreende ou ao que não se aceita na história e exercendo papel importante na reafirmação de identidades sociais, o mito
6. O conceito de neofascismo aqui empregado é compreendido nos termos definidos por Umberto Eco (1995) como "Ur-Fascismo ou Fascismo eterno". Trata-se de uma "nebulosa" com características peculiares, mas que não constituem um sistema, podem muitas vezes se contradizerem e estão também presentes em outras formas de despotismo, são elas: (1) culto da tradição; (2) recusa da modernidade; (3) culto da ação pela ação; (4) não aceitação de críticas; (5) medo da diferença; (6) apelo às classes médias frustradas;

(7) obsessão pelo complô; (8) sentimento de humilhação pela riqueza ostensiva e pela força do inimigo;

(9) princípio da guerra permanente; (10) elitismo; (11) culto do heroísmo; (12) desdém pelas mulheres e condenação de hábitos sexuais não conformistas;

(13) "populismo qualitativo"; (14)

"Novilíngua" (Eco, 1995). 
7. O Foro de São Paulo (FSP) é uma organização criada em 1990, a partir de um seminário internacional promovido pelo Partido dos Trabalhadores (PT), no qual estiveram presentes partidos e organizações da América Latina e Caribe para discutir alternativas às políticas neoliberais dominantes no continente e promover a integração latinoamericana no âmbito econômico, político e cultural. A primeira reunião do Foro foi realizada em São Paulo e, desde então, tem acontecido a cada um ou dois anos, em diferentes cidades da América Latina. Atualmente, mais de 100 partidos e organizações políticas participam dos encontros. As posições políticas variam dentro de um largo espectro, que inclui partidos socialdemocratas, extrema-esquerda, organizações comunitárias, sindicais e sociais relacionadas à esquerda católica, grupos étnicos e ambientalistas, organizações nacionalistas e partidos comunistas (<http:// forodesaopaulo. org $>$ ). do complô termina funcionando como instrumento poderoso para a exclusão dos diferentes e justificador de fracassos.

O apelo ao mito do complô encontra-se ainda claramente presente no discurso de certos formadores de opinião, alinhados ao que se poderia admitir como de extrema direita (Olavo de Carvalho, Beatriz Kicis, Marcello Reis, Raquel Sheherazade, Bolsonaro, Feliciano e o Movimento Revoltados Online) e, principalmente, ao que se refere a ideia-força do "bolivarianismo".

Desde que, em 1999, após a promulgação de uma nova Constituição, o presidente venezuelano Hugo Chávez declarou o seu país uma "República Bolivariana", convencionou-se chamar de bolivarianos os governos de esquerda na América Latina que questionaram o neoliberalismo e o Consenso de Washington. De forma semeIhante, tal retórica foi utilizada para caracterizar as presidências de Rafael Correa, no Equador e a de Evo Morales, na Bolívia. Embora os Governos de Luiz Inácio Lula da Silva e de Dilma Rousseff nunca tenham aderido formalmente a posicionamentos análogos, foram frequentes as acusações de que estariam "transformando o Brasil numa Venezuela", por parte dos políticos da oposição e de setores da mídia e da opinião pública. Para os formadores de opinião da extrema direita aqui analisados, há notória articulação entre a ideia de bolivarianismo e o comunismo, principalmente, por intermédio de uma organização denominada Foro de São Paulo?. O Foro de São Paulo assume - particularmente nos discursos de Olavo de Carvalho, Beatriz Kicis, Marcelo Reis e Bolsonaro - a hipérbole retórica da "personificação do Mal", a qual se aproxima de forma característica aos delírios de perseguição.

A função do Brasil é ser o celeiro do movimento comunista. O Foro de São Paulo é a maior organização política que já existiu no continente, tem 200 partidos, organizações de narcotraficantes, as Farc, sequestradores, o MIR chileno, Fernandinho Beira-Mar (Olavo de Carvalho, <https://youtu.be/wnzhrr1RIT4>).

O Foro de Brasília entrou com um projeto de lei no Congresso, para que a foice e o martelo sejam proibidos, da mesma forma que os símbolos nazistas são para qualquer forma de manifestação. Tem que acabar com o símbolo, eles são perniciosos e se eles ficarem ali, eles ressurgem. O comunismo é uma doença que cega e inebria os sentidos... (Beatriz Kicis, postagem Facebook 26 Dez. 2015).

Os cidadãos argentinos deram o seu recado quanto aos males produzidos ao longo de anos de bolivarianismo...Esperamos que em 2018, o Brasil também nas urnas dê um fim ao mal que assola nossa nação, em detrimento do Foro de São Paulo... criado por Lula (PT) e Fidel Castro para garantir a manutenção do ideal fracassado que é o socialismo, utilizando o suor de seus cidadãos pagadores 
de impostos para se garantirem no poder \#ForaForoDeSãoPaulo (Bolsonaro, postagem Facebook 07 Dez. 2015).

A narrativa mítica do complô - ainda que mantenha vínculos com dados factuais, inerente a toda construção mitológica - estabelece uma verdadeira transformação qualitativa da realidade, já que, na maioria das vezes, não só ultrapassa qualquer ordem cronológica, como abdica da relativização dos fatos e situações históricas. Aqui, novamente e de forma mais visível, o hiato entre o substrato histórico dos fatos e a sua leitura mítica atinge amplitude considerável. O fascista crê, firmemente, que esteja em marcha uma conspiração, empunhada por uma sociedade secreta, cujos contornos não estão e nem precisam ser muito esclarecidos. Os supostos inimigos podem ser desde organizações, partidos, a grupos específicos: os comunistas, os negros, os gays, as feministas e todos aqueles que não compartilham de seu universo mental. Sua visão de mundo é maniqueísta e encontra-se dividida entre os que representam "o Bem" e os que representam "o Mal". Essa é, portanto, uma interpretação "despolitizada" da realidade, na medida em que opera o deslocamento para o plano moral daquilo que é produto da ação humana e não da ordem da natureza. Tende, por isso, a desconectar as falas do movimento histórico no qual se originam (Barthes, 1989). Fica-se, assim, na presença de indivíduos e de movimentos sociais que alimentam fobias e preocupações generalizadas, acirrando discursos que incitam à violência e à intolerância. Mostram-se fartamente preconceituosos, ratificando que as diferenças entre "nós" e "eles" são de fundo e irreconciliáveis. Arregimentam igualmente públicos que - desorientados em meio a uma crise que, além de econômica, política é também cultural - se sentem ameaçados pelo desmoronamento de seu mundo, sendo facilmente cooptados para a defesa de causas anti-igualitárias e soluções despóticas.

O moralismo é outro campo semântico fértil explorado por esses formadores de opinião e envolve ideias de cunho claramente conservador. O conservadorismo é aqui entendido como forma de resistência às transformações promovidas pela sociedade moderna (expansão dos direitos individuais, secularização e cosmopolitismo) e uma reafirmação dos pilares da sociedade tradicional: a família, a religião e a nação (Hirschman,1992). Tal tríade está fortemente entrelaçada no discurso dos formadores de opinião da direita, apesar de apresentar graus de centralidade e radicalismo distintos. Os elementos discursivos que com maior frequência se relacionam a ideia-chave de "família tradicional" são os seguintes: oposição ao casamento entre pessoas do mesmo sexo, oposição ao aborto, à ideologia de gênero nas escolas, à expansão do feminismo e a concordância com a "cura gay". Os conteúdos centrais da ideia-força "resgate da fé cristã" envolvem emissões que invocam a entrega dos destinos individuais e coletivos "nas mãos de Deus", a profusão de mensagens de 
salmos e provérbios bíblicos, além da crítica ao que denominam de "cristofobia", atribuída à esquerda. Por último, e ao que se refere à leitura do "patriotismo" no discurso desses atores sociais, convém destacar o seu vínculo umbilical à ideia do "anticomunismo" (guerra permanente a esse inimigo comum), as louvações às Forças Armadas e os incentivos a adoração dos símbolos nacionais, com destaque para o hino e a bandeira.

Segundo os idiotas, todo homofóbico seria um gay enrustido, logo se um gay se olhar no espelho é capaz de se matar e ainda entrar para a estatística de homofobia. Os ativistas são uns afetados. Finalizo deixando meus respeitos aos gays que não colocam sua sexualidade acima da competência e se valorizam pelo que produzem ou por seus valores, não por fazer sexo com a "orelha!" (Bolsonaro, postagem Facebook, 02 Jul. 2015).

Compete a mim como pai, a você como mãe educar os seus fiIhos... criar os seus filhos, assistir aos seus filhos...o Estado não pode se intrometer na minha vida familiar. Não deixe que o movimento LGBT interfira nisso! Isto é uma questão de foro íntimo, de pais e mães... NÃO À IDEOLOGIA DE GÊNERo! (Marco Feliciano, $<$ https://youtu.be/U,CA8Z1qDqbM>).

Sua contribuição financeira ajudará para continuarmos nesta GUERRA entre o BEM e o MAL, não temos ninguém por trás de nós... partido ou político, só temos Deus na nossa FRENTE...e muita disposição para ver um futuro melhor para a nossa nação...Nossos filhos e netos nos agradecerão e muito, se deixarmos a omissão e partirmos para a ação! Porque juntos somos mais FORTES! E com Deus somos IMBATíveis! (Marcello Reis, postagem Facebook, 22 Set. 2015).

Dalrymple (psiquiatra) considera desumano e sensacionalista isentar a mulher totalmente de culpa ou responsabilidade, quando ela é vítima recorrente de agressões. Ele conheceu várias e perguntava porque não abandonavam os parceiros agressores. As respostas variavam, mas sempre em torno de uma vitimização que trazia algum gozo a elas (Rodrigo Constantino, postagem Facebook, 22 Abr. 2015)

As emissões discursivas presentes no campo semântico do "conservadorismo moral" envolvem de forma extremada conteúdos de natureza homofóbica, sexista, racista e xenófoba. Tais intolerâncias se repetem da mesma forma, como não poderia deixar de ser, nas duas outras ideias-força desveladas na pesquisa: o superdimensionamento da criminalidade e da violência no país e a oposição às cotas raciais. Desdobram-se, a partir da primeira, questões relacionadas ao apoio à redução da maioridade penal, ao recrudescimento das penas judiciais, à truculência das ações policiais e às críticas à política de direitos humanos, à justiça brasileira e à política 
do desarmamento. Com relação às cotas raciais, a conexão com outra ideia-força também presente no discurso desses atores é imediatamente observada. Isto é, há a percepção unânime de que as cotas raciais ferem o princípio da meritocracia e acirram o racismo no país.

Os marginais ditos "de menor" sabem aproveitar bem a janela de impunidade do ECA, que se fecha aos 18 anos. Respondendo como adultos, não teriam mais o séquito de patéticos ativistas dos direitos desumanos querendo aparecer, advogados de rapina em busca de fama instantânea para promover suas bancas, sem falar nos demagógicos políticos de esquerda que costumam, nessas horas, vociferar o bolorento mantra da "coitadização" dos criminosos, principalmente, dos menores. Na lógica enviesada dos defensores de bandidos, assassinos, ladrões, traficantes, sequestradores e estupradores não passam de vítimas da sociedade, como se a pobreza fosse desculpa para o crime, salvo conduto para o criminoso. E se eles são as vítimas, quem seriam os algozes? Nós? Eu não aceito essa culpa! (Raquel Sheherazade, postagem Facebook 28 Maio 2015).

Mas, assim como criminosos e psicopatas não seguem leis, esquerdistas dispensam a realidade e criam suas próprias relações de causa e efeito. [...] O único efeito do desarmamento, ao contrário, seria deixar o caminho aberto para as próximas - para Farc, PCC, Comando Vermelho, ADA, atiradores escolares etc. Sem prender bandidos, sem vigiar fronteiras, sem combater o tráfico, sem investir em cadeias e manicômios, o governo já nos trouxe a "pacificação". Agora, só pede que entreguemos nossas armas (Felipe Moura Brasil, 14 Abr. 2015).

Todo negro que é contra esse vitimismo, que são as cotas raciais, deve ser atacado e deve ser perseguido. O movimento negro, hoje, no Brasil, faz um verdadeiro trabalho de capitão do mato, perseguindo todos aqueles que não concordam com as suas ideias, que destoam de seu discurso. As cotas raciais acabam por reforçar o racismo. Na verdade, somos todos iguais, temos as mesmas capacidades e não precisamos de um privilégio ou de outro (Fernando Holiday, <https://www.YouTube.com/watch?v=nIJ_St4tt7A\&feature=share $>$ ).

A incapacidade desses agentes em lidar com a heterogeneidade, seja ela de cunho étnico, religioso, econômico, político ou ideológico, revela - como nos lembra Hannah Arendt - que

o "estranho" é um símbolo assustador pelo fato da diferença em si, da individualidade em si, e evoca essa esfera [da vida privada] onde o homem não pode atuar nem mudar e na qual tem, portanto, uma definida tendência a destruir (Arendt: 1989: 335). 
Medo e impotência diante do incompreensível num contexto de grande frustração social - aí se encontra o cadinho para a experiência totalitária.

Alia-se à intolerância à diferença, a revolta particular da classe média brasileira em ter que dividir os espaços sociais habitualmente monopolizados por ela e o medo da perda de seus privilégios. Nos últimos 13 anos ocorreram mudanças significativas no padrão de consumo das camadas mais pobres de nossa sociedade. Mais de 20 milhões de pessoas ultrapassaram a linha da pobreza, houve aumentos reais e contínuos no salário mínimo e os programas de transferência de renda, como o Bolsa Família, e de inclusão social, como as ações afirmativas, produziram transformações concretas nos padrões de integração e exclusão sociais no país (Avritzer, 2016). Um novo segmento social com capacidade de consumo de bens duráveis e não duráveis passou a ocupar espaços e a dividir o uso de serviços, nunca antes compartilhados pela classe média nacional com outras camadas mais pobres da população (aeroportos, shoppings, universidades e planos de saúde). Mais do que dividir espaços, as manifestações de ódio da classe média brasileira, durante os protestos de 2015, expressavam o seu pânico em perder privilégios seculares. Privilégios esses que obviamente não são vistos como tais, mas enquanto resultado natural de um processo justo de concorrência e mérito (Souza, 2015).

A introdução das cotas raciais nas universidades públicas e em outros concursos produziu, em especial, um efeito duplamente elucidativo no dimensionamento desta revolta. As cotas não só reduziram os espaços sociais que antes eram concebidos como reservas de mercado para classe média, como colocaram em cheque a validade prática e normativa dos mecanismos meritocráticos, que são fundantes para a organização da cosmovisão desta classe (Cavalcante, 2015). A meritocracia é, como nos ensina Pierre Bourdieu (2007), uma ideologia que serve de base ao consenso social e político das sociedades capitalistas, justamente por ocultar a produção social dos desempenhos diferenciais entre os indivíduos, transmutando-os em "qualidades inatas". É, pois, fonte basilar para a naturalização das desigualdades e legitimação da hierarquia social. Encontra-se, assim, claramente articulada às críticas relacionadas às cotas sociais e justifica o "sucesso" das classes médias nas disputas por bens materiais e simbólicos.

Como se observa no Quadro 1, a meritocracia é uma das ideias-força presente no campo semântico "princípios neoliberais", o qual similarmente apresenta outras "chaves de leitura", a saber: Estado mínimo, eficiência do mercado, livre iniciativa e corte de políticas sociais. Em verdade, tais concepções professam de maneira articulada a defesa inconteste da economia de mercado sob a égide do neoliberalismo. 
O neoliberalismo é aqui compreendido, à luz da tese de Pierre Dardot e Christian Laval (2016), como "racionalidade", antes do que como ideologia ou política econômica. Uma racionalidade de nosso "cosmo social", que

tende a estruturar e a organizar não apenas a ação dos governantes, mas até a própria conduta dos governados. A racionalidade neoliberal tem como característica principal a generalização da concorrência como norma de conduta e da empresa como modelo de subjetivação (Dardot \& Laval, 2016: 17).

O neoliberalismo é, nesta perspectiva, um "sistema normativo" que abarca discursos e práticas que expandem a lógica do capital a todas as esferas e relações sociais. No âmbito do discurso dos formadores de opinião, verificam-se níveis de complexidade e sofisticação diversos nas discussões acerca dos princípios neoliberais apontados, revelando certo desconcerto entre um maior domínio intelectual sobre o tema e a simulação de adesão a partir da repetição de "chavões" clássicos do ideário liberal. Não obstante, a lógica da concorrência e o modelo de empresa, como normas de conduta e subjetivação, encontram-se claramente expressos em suas emissões discursivas. A exaltação da livre iniciativa, a certeza da capacidade empreendedora dos indivíduos e a total desconfiança em relação ao Estado como administrador dos negócios públicos, são indicadores da introjeção desta "razão do mundo" (Dardot \& Laval, 2016).

O que nós precisamos nas esferas municipais, estaduais e federal é de pessoas que digam de forma muito clara que o Estado somente atrapalha a vida do cidadão. É você que faz a sua vida melhorar, é você que consegue alcançar o sucesso. Mas para isso, você precisa ter um caminho livre, um caminho livre de pedras, de buracos causados pelo Estado. Precisa estar livre do peso que você carrega nas costas, com a burocracia e com os impostos... Acredito que quando tivermos finalmente este caminho livre, quando o brasileiro puder correr atrás de seu sucesso, sem peso nas costas e sem buracos na estrada, nós conseguiremos ter um país desenvolvido e um país mais justo para todos (Fernando Holiday, <https://www. YouTube.com/watch?v=nIJ_St4tt7A\&feature=share $>$ ).

O MBL defende que mais dinheiro e mais poder fique nas mãos das pessoas, dos cidadãos e das comunidades e menos nas mãos dos políticos. Como seria isso? Significa diminuir impostos, diminuir o número de empresas estatais, tirar a gestão pública de escolas e hospitais, profissionalizar a gestão para um atendimento melhor e para que os políticos não tenham margem para indicação desse tipo de cargos para corrupção, como aconteceu no escândalo da Petrobrás (Kim Kataguiri, <https://youtu.be/OWvaF56u2jU>). 
O Movimento Vem Pra Rua tem três pilares: a defesa dos preceitos democráticos, a ética na política e o Estado desinchado e eficiente... não somos a favor de nenhuma forma de golpe, de nenhuma forma de intervenção militar e nada que não seja constitucional. As coisas têm que acontecer dentro da lei e vão acontecer dentro de princípios republicanos. É o que defendemos (Rogério Chequer, <http://webcache.googleusercontent.com/search?>).

Observa-se nos discursos dos formadores de opinião, e em particular naqueles que defendem com veemência os princípios neoliberais (Kim Kataguiri, Fernando Holiday, Rogério Chequer e Rodrigo Constantino), certa regularidade de formas e conteúdo a indicarem uma produção discursiva claramente padronizada. Suspeita-se que a unidade desses conteúdos venha a ser obra da atuação massiva dos think tanks de direita no Brasil, nos últimos anos e, em especial, da Atlas Network. De acordo com Camila Rocha (2015), o objetivo principal dos think tanks "ativistas" de direita na América Latina é o de difundir o ideário liberal de maneira expansiva, de modo a facilitar a proposição de políticas públicas alinhadas à "defesa do livre mercado" e à aprovação das mesmas pelas instâncias estatais. Estar alinhado à "defesa do livre mercado" significa fundamentalmente:

Pressionar pela adoção de medidas que incentivem a abertura de mercados, os cortes de gastos do Estado e a privatização de empresas estatais (Rocha, 2015: 270).

Merece ainda destaque o fato de que hoje praticamente todos os mais importantes think tanks de direita do mundo, fazerem parte da rede constituída pela Atlas Network (Rocha, 2015). Na América Latina e nos últimos dez anos mais do que dobrou o número de think tanks ligados à Atlas Network e entre eles se encontram: o Instituto Millenium, que tem Rodrigo Constantino como um de seus fundadores, o MBL e o Vem pra Rua, ainda que esses movimentos não reconheçam formalmente tal filiação (<http:// apublica.org/2015/06/a-nova-roupa-da-direita/\#.WApss1Jly3A.email>).

Interessante examinar, no discurso desses agentes sociais, a convivência de elementos claramente contraditórios aos princípios neoliberais que defendem. São ferozes partidários do Estado mínimo, porém pressionam de todas as formas o Estado a criar situações de concorrência e a incentivar modelos de comportamento que direcionem a conduta dos indivíduos no sentido de transformá-los em consumidores e empreendedores. Propagandeiam a defesa do livre mercado numa economia global, mas recorrem constantemente ao discurso de salvação da pátria. Pregam a livre iniciativa, embora não reconheçam direitos individuais básicos. Enfim, há que se admitir, como apontam Dardot e Laval (2016), que o neoliberalismo em sua for- 
ma atual, apresenta-se como uma "razão do mundo" de natureza antidemocrática. Seu antidemocratismo denuncia-se quando se constata que ele é reconhecido na contemporaneidade como a única verdade e alternativa possível para o desenvolvimento das nações. Outrossim, encontra-se ainda presente na submissão de todos a um regime de concorrência universal em que

\begin{abstract}
as formas de gestão na empresa, o desemprego e a precariedade, a dívida e a avaliação apresentam-se como poderosas alavancas de disputa interindividual e definem novos modos de subjetivação. A polarização entre os que desistem e os que são bem-sucedidos mina qualquer solidariedade e cidadania expandida (Dardot \& Laval, 2016: 9).
\end{abstract}

\title{
Considerações finais
}

A apreensão da cosmovisão (weltanschauung) dos principais formadores de opinião que deram suporte ideológico e coordenaram a ação dos manifestantes de direita no Brasil, em 2015, coloca-se como desafio intelectual de indiscutível relevância e atualidade. O desvelamento e a compreensão dos conteúdos centrais que envolvem as emissões discursivas desses agentes sociais revelam-se não só importantes para o reconhecimento do caráter ativo e reflexivo desses sujeitos como produtores de sentido, mas, principalmente, para a identificação dos enquadramentos que orientaram grande parte da população brasileira a se localizar no espaço político, ao longo do período considerado.

O artigo acaba também por se inserir num plano de análise ainda pouco explorado, o qual aponta para a exacerbação de posicionamentos fascistas em nosso país. Longe de ser uma particularidade brasileira, esse fenômeno vem se desenrolando em outras partes do planeta. Para Dardot e Laval (2016), o recrudescimento dos movimentos conservadores e mesmo os de caráter fascista tem sua raiz nas transformações subjetivas provocadas pela hegemonia neoliberal, no sentido do fortalecimento do egoísmo social e da recusa à redistribuição e à solidariedade.

Para Nancy Fraser (2017), o avanço dos movimentos e dos governos de direita no mundo sinalizam, em verdade, um colapso da hegemonia neoliberal. Os motins eleitorais expressos na vitória de Donald Trump nas eleições norte-americanas, o voto Brexit no Reino Unido e o crescimento do apoio à Frente Nacional na França compartilham entre si a rejeição de grande parte do eleitorado desses países

à letal combinação de austeridade, livre comércio, dívida predatória e trabalho precário e mal remunerado, que caracterizam o capitalismo financeirizado contemporâneo (Fraser, 2017). 
Segundo a autora, tais insubordinações indicam, sobretudo, a déblacle de um tipo particular de neoliberalismo, aquele que floresceu durante os últimos governos democratas norte-americanos. É o "neoliberalismo progressista", o qual mesclou formas perversas de financeirização com certos ideais de emancipação (feminismo, antirracismo, multiculturalismo e direitos LGBTQ). É essa aliança complexa que os eleitores norte-americanos, assim como os de outros países, passaram a rejeitar. Em outros termos e por estarem combinados, o repúdio aos efeitos perversos da globalização acabou por defenestrar o liberalismo cosmopolita identificado com ela.

Finalmente, a expansão dos movimentos de direita e até mesmo fascistas no mundo e, em particular no Brasil, nos leva a permanecermos atentos, como bem nos lembra Foucault:

[...] o fascismo está em todos nós, assombrando nossos espíritos e nossas condutas cotidianas [...] nos fazendo amar o poder e a desejar esta coisa que nos domina e nos explora (Foucault, 1977: 12).

As polarizações políticas assistidas nos últimos anos na vida política brasileira, e acirradas pelo aprofundamento da crise econômica, são exemplos ilustrativos dessa predição foucaultiana. Elas acabam por inviabilizar o diálogo democrático, ao aprofundar a distância entre "nós" e "eles" e impedir a construção de canais de mediação, que possibilitem a convivência respeitosa entre contrários. Eis aí o caldo cultural ideal para o agravamento de experiências autoritárias e a procura por saídas despóticas.

The right that came out of the closet:

the cosmovision of the opinion makers

of the brazilian right-wing protesters

\begin{abstract}
The article seeks to unveil the cosmovision (weltanschauung) of the main opinion-formers of the Brazilian right-wing protesters, who went to the streets during the year 2015. The work was based on multi-method research, built from the survey of Facebook posts created by these social actors, during the year in focus, as well as articles from their authorship published on blogs, newspapers and magazines, with their authorship, videos of their interviews and hangouts. The analysis was based on two focus groups composed of frank supporters and participants in the protests, in order to understand how the cosmovision of these opinion leaders was effectively shared by the right-wing protesters of 2015. In this data analysis, the systematization of certain semantic fields was applied, constituted by certain force-ideas, which present themselves in a regular and repetitive way in the discourse of such social agents. They therefore functioned as "keys of reading" for their interpretations of the national political conjuncture and as guides for their actions. These are: antipetism, moral conservatism and neoliberal principles.
\end{abstract}


Keywords: cosmovision (weltanschauung), right-wing, opinion formers, 2015 protesters, semantic fields

\section{Referências}

ALDÉ, Alessandra. A construção da política: democracia, cidadania e meios de comunicação de massa. Rio de Janeiro: Editora FGV, 2004.

ARENDT, Hannah. Origens do totalitarismo. São Paulo: Companhia das Letras, 1989.

AVRITZER, Leonardo. Impasses da democracia no Brasil. Rio de Janeiro: Civilização Brasileira, 2016.

BARTHES, Roland. Mitologias. Rio de Janeiro: Bertrand-Brasil, 1989.

BOBBIO, Norberto. Direita e esquerda: razões e significados de uma distinção política. São Paulo: Editora Unesp, 1994.

BOLTANSKI, Lüc. El Amor y la Justicia como competências: tres ensayos de sociologia de la acción. Buenos Aires: Amorrortu, 2000.

BOURDIEU, Pierre. A distinção: crítica social do julgamento. São Paulo; Porto Alegre: Editora Edusp; Zouk, 2007.

CAVALCANTE, Sávio. Classe média e conservadorismo liberal. In: CRUZ, Sebastião Velasco; KAYSEL, André; CODAS Gustavo (Orgs.). Direita, volver!: o retorno da direita e o ciclo político brasileiro. São Paulo: Editora Fundação Perseu Abramo, 2015.

DARDOT, Pierre; LAVAL, Christian. A nova razão do mundo: ensaio sobre a sociedade neoliberal. São Paulo: Boitempo, 2016.

ECO, Umberto. Folha de S. Paulo, “Caderno Mais!", 14 Maio 1995.

ENTMAN, Robert M. Democracy without citizens: media and the decay or american politics. New York: Oxford University Press, 1989.

FOUCAULT, Michel. O anti-édipo: uma introdução à vida não fascista. Cadernos de Subjetividade do Núcleo de Estudos e Pesquisas da Subjetividade do Programa de Estudos Pós-Graduados em Psicologia Clínica da PUC-SP, v. 1, n. 1, p. 197-200, 1993.

FRASER, Nancy. El final del neoliberalismo progressista, 2017. Disponível em: <https://www.dissentmagazine.org/online_articles/progressive-neoliberalism-reactionary-populism-nancy-fraser>. Acessso em: 12 Jan. 2017 
GILL, Rosalind. Análise do discurso. In: BAUER, Martin W.; GASKELL, George (Orgs.). Pesquisa qualitativa com texto, imagem e som: um manual prático. Petrópolis: Vozes, 2002.

GIRARDET, Raoul. Mitos e mitologias políticas. São Paulo: Companhia das Letras, 1987.

GOFFMAN, Erving. Os quadros da experiência social: uma perspectiva de análise. Petrópolis: Vozes. 2012.

HIRSCHMAN, Albert. A retórica da intransigência: perversidade, futilidade, ameaça. São Paulo: Companhia das Letras, 1992.

MAINGUENEAU, Dominique. Novas tendências em análise do discurso. Campinas: Pontes, 1993.

MCGANN, James G. Global go to think tank index report. Filadelfia: University of Pennsylvania, 2015.

ORTELLADO, Pablo; SOLANO, Ester. Pesquisa manifestação política 12 de abril de 2015. Disponível em: <http://gpopai.usp.br>. Acesso em: Maio 2015.

ORTELLADO, Pablo.; SOLANO, Ester.; NADER, L. Pesquisa manifestação política 16 de agosto de 2015. Disponível em: <http://gpopai.usp.br/pesquisa/>. Acesso em: Ago. 2015.

PIERUCCI, Antônio Flávio. Ciladas da diferença. Tempo Social, v. 2, n. 2, p. 7-37, 1990.

—. As bases da nova direita. Novos Estudos Cebrap n. 19, p. 26-45, 1987.

RAGO, M.; VEIGA-NETO, A. (Orgs). Para uma vida não facista. Coleção "Estudos Foucaultianos". Belo Horizonte: Autêntica, 2009.

ROCHA, Camila. Direitas em rede: think tanks de direita na América Latina. In: CRUZ, Sebastião Velasco; KAYSEL, André; CODAS Gustavo (Orgs.). Direita, volver!: o retorno da direita e o ciclo político brasileiro. São Paulo: Editora Fundação Perseu Abramo, 2015 .

RIEDER,Bernhard. Studying Facebook via data extraction: the Netvizz application. In: Annual ACM Web Science Conference, 5, p.346-355, 2013, Paris. Proceedings...,2013. Disponível em: <http://thepoliticsofsystems.net/permafiles/rieder_websci.pdf>. Acesso em:12 Maio 2017

SOUZA, Jessé. A tolice da inteligência brasileira: ou como o país se deixa manipular pela elite. São Paulo: LeYa, 2015. 
TATAGIBA, Luciana; TRINDADE, Thiago; TEIXEIRA, Ana Claudia C. Protestos à direita no Brasil (2007-2015) . In: CRUZ, Sebastião Velasco; KAYSEL, André; CODAS Gustavo (Orgs.). Direita, volver!: o retorno da direita e o ciclo político brasileiro. São Paulo: Editora Fundação Perseu Abramo, 2015.

TELLES, Helcimara de Souza. Corrupção, legitimidade democrática e protestos: o boom da direita na política nacional? Revista Interesse Nacional, Ano 8, n. 30, Jul.-Set. 2015a.

- O que os protestos trazem de novo para a política brasileira? Em Debate, v. 7, n. 2, p. 7-14, Abr. 2015b.

VEIGA, Luciana; GONDIM, Sonia Maria G. A. Utilização de métodos qualitativos na ciência política e no marketing político. Opinião Pública, v. 7, n. 1, p. 1-15, 2001.

WEBER, Max. A objetividade do conhecimento na ciência social e na ciência política. Metodologia das ciências sociais, v. 1. São Paulo: Editora Unicamp, 1992. 